\title{
Green Construction Materials and the Circular Economy
}

\author{
J Pacheco ${ }^{1 *}$, F Leitão², J de Brito ${ }^{3}$ and J Bordado ${ }^{4}$ \\ ${ }^{1}$ Researcher, c5LAb - Sustainable Construction Materials Association, Portugal \\ ${ }^{2}$ Industrial Affairs \& Sustainability Director, ATIC - Technical Association of the Cement Industry / c5Lab, Portugal \\ ${ }^{3}$ Full Professor, IST, University of Lisbon / c5Lab, Portugal \\ ${ }^{4}$ Full Professor, IST, University of Lisbon, Portugal
}

*Corresponding author: J Pacheco, Edifício Central Park, Rua Central Park 6, 2795-242 Linda-a-Velha, Portugal.

Received Date: March 05, 2021

Published Date: April 06, 2021

\begin{abstract}
This opinion article concerns the minimization of the environmental impacts of the cement and concrete industries. The article identifies the processing of carbon dioxide that results from cement production and the incorporation of construction and demolition waste on concrete as key objectives for environmental sustainability, discusses concepts related to both objectives, and presents the mission of c5Lab - Sustainable Construction Materials Association, a consortium that intends to contribute to the greening of the cement and concrete industries.
\end{abstract}

Keywords: Sustainability; cement; concrete; carbon dioxide; construction and demolition waste; circular economy

\section{Introduction}

Reinforced Concrete stands as the main Structural material for large buildings and many other Civil Engineering works, with many emblematic structures, from the Roman Empire (e.g., the dome of the Roman Pantheon) to the recent trend for tall skyscrapers, which are remarkable accomplishments of the concrete industry (e.g., the one-kilometre-tall Jeddah Tower, currently under construction Figure 1). The sustainability of the concrete industry is an emerging trend, because of public perception, legislation, and the drive of industrial agents towards more environmentally friendly practices. Any mitigation of the impacts of the production both cement and concrete have relevant beneficial effect on the environmental sustainability of the construction sector, due to the large overall volume of production of the concrete industry, in comparison to those of all other construction materials. The production of cement has large environmental impacts and significant efforts have been made in the last decades by the cement industry towards reduction of cost and impacts associated to energy spent in the production of cement. However, carbon dioxide is necessarily produced during this process and strategies to use this carbon dioxide as a raw material are urgently needed. At the same time, the large volume of production implies that a significant amount of construction and demolition waste (CDW) may be incorporated in construction materials, reducing landfill disposals and the extraction of mineral resources. This opinion article treats two very relevant topics for the sustainability of construction: the reduction of the carbon footprint of cement production and the use of CDW in concrete. Both are key strategic areas of c5Lab, sustainable construction materials association, a consortium composed of the two Portuguese cement producers and leading Portuguese universities that targets the environmental best practice for the cement and concrete industries. 


\section{Carbon Dioxide from Cement Production: Process- ing Needs of a Raw Material}

The modern cement industry supports the promotion of industrial symbiosis and the recognition of energy recovery as a waste management solution for non-recyclable waste. The use of waste materials, such as (refused-derived fuel) RDF, in the cement industry with a simultaneous energy recovery and material recycling, referred to as co-processing, contributes towards achieving the objectives of the circular economy. However, clinker production requires, as a precursor step, the conversion of Calcium Carbonate into the respective oxide, and this leads to a significant balance of carbon dioxide emission. The reversal of the progression of climate changes imposes a reduction of the carbon dioxide emissions, and their valorization whenever possible, but at feasible costs. Production of fuels, such as methane, from carbon dioxide, is being optimized all over the World, but to convert the more oxidized form of carbon to the lowest oxidized one, one must use a large amount of Hydrogen, and very specific catalysts. Conventional production of Hydrogen by steam reforming, from natural gas or from crude fractions is not a sustainable option, and the best alternative seems to be "Green Hydrogen" produced by water electrolysis using photovoltaic energy. The separation of the carbon dioxide from the effluent gases (capture) can be performed by absorption in aqueous amine solutions, followed by heat induced regeneration, but alternative processes are being developed (pressure swing absorption and membranes). The use of Oxygen, instead of air, for the combustion (oxyfuel processes) seems to be an alternative, but from the engineering point of view it is still at a technological readiness level (TRL) of 5, and the large reduction in capture cost does not compensate for the additional investment and higher operating costs.

\section{Incorporation of Construction and Demolition Waste in Concrete}

The generation of CDW is ever increasing worldwide because of the increase of World population, urbanization, and increased standards of comfort that result in refurbishments and demolitions. This is a well-identified problem by governing bodies and is leading towards increasingly stringent legislation to enforce CDW recycling. In the case of the European Union, over the last 20 years the generation of CDW has steadily increased and consistently corresponded to $30 \%$ to $36 \%$ of all waste produced [1]. EU Directive 2008/98/EC [2] sets a minimum of $70 \%$ of non-hazardous CDW re-use/recycling and this goal has been fulfilled in most EU member states, yet there is strong reliance on backfilling and landfilling operations. For a relevant portion of CDW, this is a clear down cycling of a product that could be used for higher-end applications, leading to the reduction of the consumption of natural resources and to the adoption of circular economy concepts. Because of concerns of this type, EU-Directive-2018/851 [3] amended EU Directive 2008/98/EC towards more restrictive criteria for backfilling. Similar reasoning and recommendations have been made in other regions (state-wide policies in the United States of America may be consulted in [4]). More restrictive legislation towards CDW recycling is expected in the immediate future and construction agents need to find systematic ways to incorporate CDW in their materials. Out of all construction materials, concrete offers the best possibilities for CDW recycling due to several aspects, including its overall volume of production and the fact that concrete is produced with different constituents (e.g., aggregates, filler, cement, supplementary cementitious materials) and each may be separately replaced by specific products of CDW processing. Typically, CDW is processed at licensed units and, after removal of deleterious materials, CDW is crushed and sieved into smaller particles. This process results in recycled aggregates and finer fractions of recycled materials that do not have a clearly defined use for routine applications, resulting in massive deposits in CDW plants. These deposits are, in practical terms, landfills (Figure 2). As a matter of fact, the state-of-the-art and standardization of the use of recycled materials in concrete is at very different maturity levels and this prevents a full-recycling approach towards CDW:

1. Concrete with incorporation of coarse recycled aggregates - research is comprehensive, the behaviour of this type of concrete is well-understood and complies with expectations (Fig. 3 [5]), standards already include recommendations and/ or specific clauses for its application, and research priorities concern specific topics.

2. Concrete with incorporation of fine recycled aggregates - research is not as comprehensive and standards have more stringent conditions for the applicability of fine in comparison with coarse recycled aggregates. Research priorities for fine recycled aggregates still include general material's characterization.

3. Finer fractions of waste as filler, supplementary cementitious materials or as a raw kiln material for cement production - emerging research, with a relatively small number of publications.

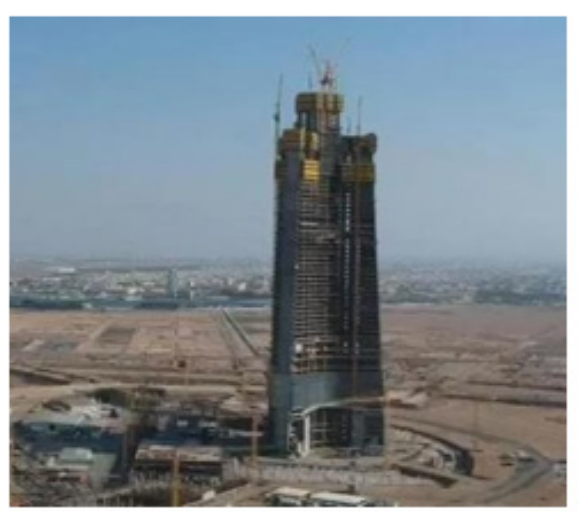

Figure 1: Jeddah tower, a one-kilometre-tall concrete building (under construction). 
4. Part of the mission of c5Lab is to understand what applications are best suited to each type of CDW. The aforementioned applications of CDW on concrete are either under study by c5Lab or are identified as future research (Figures 1-3).

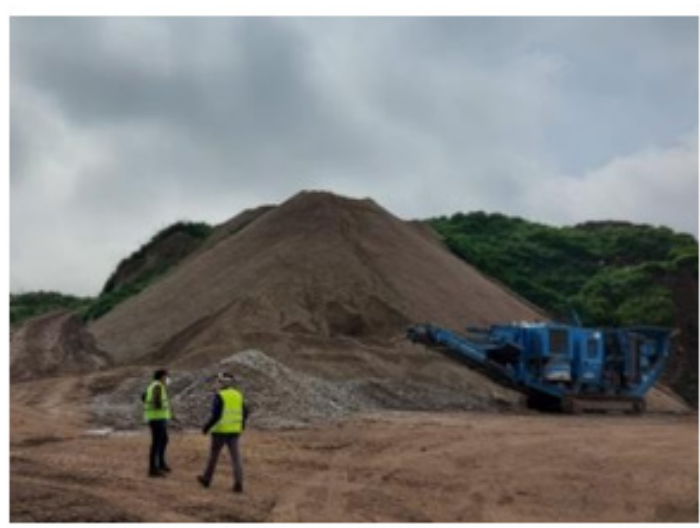

Figure 2: CDW plant with stockpile of recycled material with possible application in concrete.

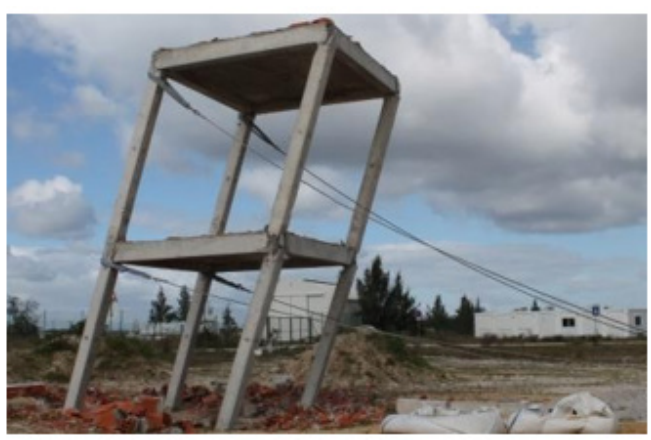

Figure 3: Structural test on the seismic behaviour of concrete with coarse recycled aggregates [5].

\section{Conclusion}

The cement and concrete industries have much to offer in terms of helping the countries achieve their circular economy goals. All forms of recycling should be encouraged and assessed in order to ensure that the best environmental, social and economic outcomes are achieved. Today, the Green Cement - Concrete Life Cycle Assessment (LCA) comprises the compilation and evaluation of all inputs, outputs and environmental impacts of these products during all their life cycle: clinker - cement - concrete - construction - demolition with materials recycling. Concrete can be recycled $100 \%$ at the end of its service life. The cement - concrete production's main circular economy principles can be summarized in terms of co- processing (combination of both energy recovery and material recycling), the utilization of $\mathrm{CO}_{2}$ emissions derived fuels, the use of Alternative Raw Materials (such as the CDW, which can be used as cement raw materials, as additives for cement and as concrete aggregates), substitution of clinker with alternative constituents (such as fly ashes, granulated blast furnace slags and calcined clays) and new cement types (innovative binder technologies not requiring the actual high firing temperatures). The cement - concrete industry faces a huge challenge to reinvent itself in order to become carbon neutral sustainable and the circular economy principles play an important role in this transformation. The future cement/ concrete production will be more environmental-friendly, more energy-efficient and will be based on recycled raw materials, such as the CDW. Most of the emerging technologies required to achieve this transformation are under development stage at the Sustainable Materials Association Laboratories - c5Lab.

\section{Acknowledgment}

None.

\section{Conflict of Interest}

No conflict of interest.

\section{References}

1. Eurostat (2019) Waste generated by households and businesses by economic activity according to NACE Rev. 2 and year - [ten00106].

2. (2008) EU Directive 2008/98/EC of the European Parliament and the Council of 19 November 2008 on waste and repealing certain Directives, Official Journal of the European Union.

3. (2018) EU Directive 2018/851, of the European Parliament and of the Council of 30 May 2018 amending Directive 2008/98/EC on waste. Official Journal of the European Union.

4. (2016) Disposal bans \& mandatory recycling in the United States. Updated: November 2016. Northeast Recycling Council.

5. Pacheco J, J de Brito, Ferreira J, Soares D (2015) Destructive horizontal load tests of full-scale recycled aggregate concrete structures. ACI Structural Journal 112(6): 815-826. 